\title{
Antimicrobial activity of methylene blue and toluidine blue $O$ covalently bound to a modified silicone polymer surface
}

\author{
C. Piccirillo, ${ }^{a}$ S. Perni, ${ }^{c}$ J. Gil-Thomas, ${ }^{b}$ P. Prokopovich, ${ }^{d}$ M. Wilson, ${ }^{c}$ J. Pratten ${ }^{c}$ and I. P. Parkin $* a$ \\ Received 18th March 2009, Accepted 5th June 2009 \\ First published as an Advance Article on the web 6th July 2009 \\ DOI: 10.1039/b905495b
}

\begin{abstract}
Methylene Blue or Toluidine Blue $\mathrm{O}$ were covalently bound to an activated silicone polymer by means of an amide condensation reaction. UV-visible absorption spectra confirmed that the dye was surface bound. The new polymers with covalently attached dye display significant bactericidal activity against Escherichia coli and Staphylococcus epidermidis with a $99.999 \%$ reduction in viable bacteria after four minutes exposure to a low power laser.
\end{abstract}

\section{Introduction}

Catheters are important medical devices involved in the delivery of fluids to and from the body as well as drug administration. Catheters are typically made of flexible polymeric materials such as silicone and polyurethane. The surface of a catheter is nonshedding and often rough which means that their surfaces can readily be colonised by bacteria, causing the formation of a biofilm and this can eventually result in Catheter-associated infections (CAIs). ${ }^{1,2}$ Two of the most common sources of hospital acquired bloodstream infections are intravascular and urinary catheters, due to their extensive use in medical care. ${ }^{3}$ For example 5 million central venous catheters are used annually in the US, of which $3-8 \%$ result in bloodstream infections with an associated healthcare cost of around $\$ 25,000$ per incident and a mortality rate of $c a .15 \% .^{2}$ In addition, more than 30 million urinary catheters are inserted every year, with a $10 \%-30 \%$ rate of infection, of which $<1 \%$ result in death. ${ }^{4}$

Several methods have been employed to try to eliminate or reduce bacterial colonisation of a catheter, these include the use of silver impregnation and high dose antibiotic flushes. ${ }^{5}$ The silver approach has not been unequivocally established to be effective and the catheters are often expensive, whereas the antibiotic flush, whilst largely successful, can lead to the development of antibiotic-resistant strains of bacteria. One novel approach for the elimination of bacteria on a polymer surface is to use a light-activated antimicrobial agent (LAAA). ${ }^{6}$

LAAAs are compounds capable of killing bacteria by producing singlet oxygen and/or radicals in the presence of light and these are highly cytotoxic to bacteria. ${ }^{7}$ The use of LAAAs to treat or prevent infectious diseases is known as photodynamic therapy (PDT). ${ }^{8}$ PDT is a well-established therapy for certain

\footnotetext{
${ }^{a}$ Materials Chemistry Research Centre, Department of Chemistry, University College London, 20 Gordon Street, London, WC1H OAJ, United Kingdom.E-mail: i.p.parkin@ucl.ac.uk

${ }^{b}$ Departemento de Quimica Organica, Facultat de Farmacia, Universitat de Valencia, Avida Vincente Andres Estelles, Burjassot, Valencia, Spain ${ }^{c}$ Division of Microbial Diseases, UCL Eastman Dental Institute, University College London, 256 Gray's Inn Road, London, WC1X 8LD, United Kingdom

${ }^{d}$ Wolfson School of Mechanical and Manufacturing Engineering, Loughborough University, Loughborough, LE11 3TU, United Kingdom
}

types of cancer. ${ }^{9}$ LAAAs are usually inorganic or organic dyes such as Methylene Blue (MB) and Toluidine Blue O (TBO). We have previously shown that these dyes can be physically incorporated into a catheter material such as silicone by a swellencapsulation-shrink method, ${ }^{10-12}$ furthermore these dyeimpregnated polymers are effective at killing bacteria using white and laser light sources. ${ }^{13,14}$ In these studies, the LAAA was not directly bound to the polymer and could potentially leach from the polymer into solution. Despite this, the LAAA-polymers were very effective at killing Escherichia coli and methicillinresistant Staphylococcus aureus (MRSA).

This paper reports the first example of a LAAA covalently bound to a silicone surface. The silicone surface is relatively inert $^{15}$ and was modified to enable reaction with both $\mathrm{MB}$ and TBO. The new polymers were shown to be extremely potent against two of the most frequent causative agents of CAIs $-E$. coli and Staphylococcus epidermidis.

\section{Materials and methods}

\subsection{Reagents}

Poly(ethylene glycol) monoallyl ether (average $M W=500$ ) was purchased from Clariant UK. $N, N^{\prime}$-disuccinimidyl carbonate (97\%, anhydrous), triethylamine $(99 \%$, anhydrous) platinumdivinyltetramethyldisiloxane complex $\left((\mathrm{Pt})_{2}-\left(\mathrm{H}_{2} \mathrm{C}=\mathrm{CH}-\right.\right.$ $\left.\left.\mathrm{SiMe}_{2} \mathrm{OSiMe}_{2} \mathrm{CH}=\mathrm{CH}_{2}\right)_{3}\right), \mathrm{F}_{3} \mathrm{CSO}_{3} \mathrm{H}$ and 2-methoxyethyl ether (99\%, anhydrous) were purchased from Sigma Aldrich. Silicone rubber Sylgard 184 and $(\mathrm{MeHSiO})_{n}$ DC1107 were purchased from UNIVAR, Toluidine Blue $\mathrm{O}$ and Methylene Blue were purchased from Sigma (UK).

\subsection{Materials characterisation}

${ }^{1} \mathrm{H}$ and ${ }^{13} \mathrm{C}$ NMR spectra were recorded at $400 \mathrm{MHz}$ on a Bruker AMX 400 spectrometer at room temperature in $\mathrm{CDCl}_{3}$. IR analysis of the elastomer samples was undertaken using both Perkin Elmer RX I and Perkin Elmer Universal ATR spectrometers for measurements in transmission and reflection respectively. UV-visible absorption analysis of the elastomer samples was performed using a Helios- $\lambda$ instrument (Thermospectronic). The topography and surface roughness of each sample were examined using atomic force microscopy (AFM; 
Nanoscope IV, Digital Instruments) in the tapping mode. For all of the sample types, the scan was performed on a $25 \times 25 \mathrm{~mm}$ area at a scan velocity of $50 \mu \mathrm{m} \mathrm{s}^{-1}$ and at a scan frequency equal to $1.0 \mathrm{~Hz}$. The roughness parameter $R_{a}$ and RMS were assessed at each scan and the average values of at least five independent scans are reported. All solvents were dried by distillation prior to use.

\subsection{Reaction}

The functionalisation of the silicone and its subsequent reaction employed a modified version of that published by Chen et al. ${ }^{15}$ to activate the polymer; the complete reaction scheme is shown in Fig. 1 in the case of TBO.

2.3.1 Silicone elastomer preparation. Sylgard 184 PDMS prepolymer was mixed with the crosslinking agent at a ratio of $10: 1$. The mixture was spread uniformly on a glass surface to make a $1 \mathrm{~mm}$ thick layer. The polymer was then cured for $48 \mathrm{~h}$ under vacuum at room temperature. After curing, the elastomer sheets were cut into $1 \times 1 \mathrm{~cm}$ squares. The samples were washed with hexane and dried under vacuum.

2.3.2 Step A: surface functionalisation. Thirty $1 \times 1 \mathrm{~cm}$ squares of the cured silicone elastomer were immersed in a solution of $110 \mathrm{ml}$ of methanol, $66 \mathrm{ml}$ of DC1107 and $0.7 \mathrm{ml}$ of $\mathrm{F}_{3} \mathrm{CSO}_{3} \mathrm{H}$. The solution was stirred at room temperature for $1 \mathrm{~h}$ to functionalise the polymer surface. The functionalised elastomers 1 (Fig. 1) were then washed with methanol and hexane and dried under vacuum.

2.3.3 Step B: synthesis of $\alpha$-allyl- $\omega-N$-succinimidyl carbonatepoly(ethylene glycol) ${ }^{16}$. Poly(ethylene glycol) monoallyl ether (PEG) was dried by adding $30 \mathrm{ml}$ of toluene to $50 \mathrm{ml}$ of the glycol, then the toluene was removed under vacuum; the procedure was repeated 3 times. The dried PEG $(10 \mathrm{ml}, 0.025 \mathrm{~mol})$ was<smiles>[CH]O[Si](C)(CC[SiH3])O[Si](C)(C)O[Si](C)(C)O[Si](C)(C)O[Si](C)(C)OC</smiles><smiles>C=CCOC(C)(C)CCOC(C)(C)CO</smiles><smiles>C[Si](C)(C)O[Si](C)(C)O[Si](C)(C)C</smiles><smiles>O=C(OC1C(=O)CCC1=O)ON1C(=O)CCC1=O</smiles><smiles>CO[Si](C)(C)O[Si](C)(C)O[Si](C)(C)O[Si](C)(C)O[Si](C)(CC[SiH3])OC</smiles>

1<smiles>C=CCOC(C)(C)COC(C)(C)COC(=O)OC1C(=O)CCC1=O</smiles>

2

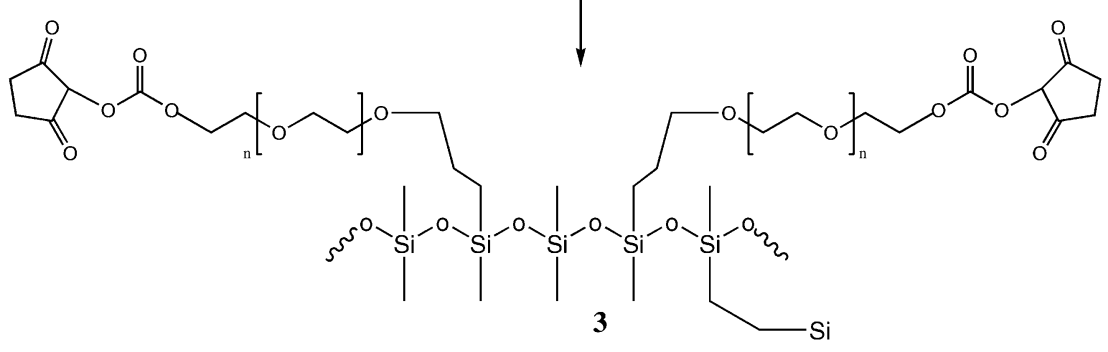

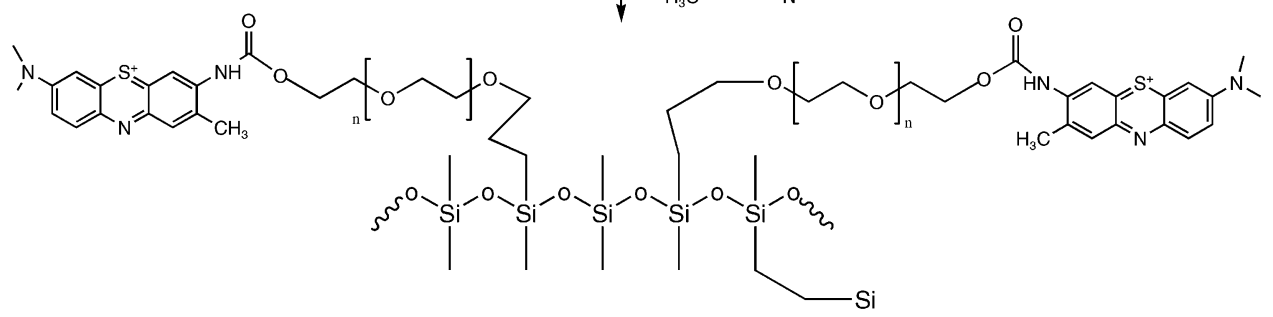

4

Fig. 1 Scheme showing the functionalisation of the silicone surface and of the subsequent reaction with Toluidine Blue O. 
dissolved in $30 \mathrm{ml}$ of acetonitrile; $12.3 \mathrm{~g}$ of disuccinimidyl carbonate and $7 \mathrm{ml}$ of triethylamine $(0.048 \mathrm{~mol})$ were added to the solution. The mixture was stirred under nitrogen for $16 \mathrm{~h}$; a whitish precipitate formed. After removing the acetonitrile under vacuum, the precipitate was dissolved in $35 \mathrm{ml}$ of dry toluene. The solution was then cooled to $0{ }^{\circ} \mathrm{C}$, the brown precipitate filtered off and the toluene removed under vacuum. This procedure was repeated twice, leaving $9.6 \mathrm{~g}$ of a yellow oil ( $\alpha$-allyl- $\omega$ - $N$-succinimidyl carbonate-poly(ethylene glycol), 2, in Fig. 1) as product (58\% yield).

2.3.4 Step C: addition of PEG derivative to the modified elastomers. The thirty samples of modified elastomers $\mathbf{1}$ (prepared as described in step A) were placed into a solution of the modified PEG derivative $(9.6 \mathrm{~g})$ in dry 2-methoxyethyl ether $(40 \mathrm{ml})$; two drops of platinum catalyst (platinum-divinyltetramethyldisiloxane complex) were added and the solution stirred under nitrogen for $17 \mathrm{~h}$. The modified surfaces 3 (Fig. 1) were washed with dry acetonitrile and dried under vacuum.

2.3.5 Step D: addition of dye. Fifteen samples of the modified elastomers 3 were immersed in a $100 \mathrm{ml}$ solution of either MB or TBO in phosphate buffered saline (PBS; concentration of dye $60 \mu \mathrm{g} \mathrm{ml} \mathrm{m}^{-1}$ ). The solutions were stirred for $24 \mathrm{~h}$ at room temperature. The samples 4 were mechanically removed from the solution and washed with copious amounts of PBS (at least three times) and dried under vacuum.

\subsection{Antibacterial tests}

The organisms used were Staphylococcus epidermidis RP62a and Escherichia coli ATCC 25922. These organisms were maintained by weekly subculture on Brain Heart Infusion (BHI) agar (Oxoid, Basingstoke, UK). For experimental purposes, the bacteria were grown aerobically in BHI broth (Oxoid) at $37^{\circ} \mathrm{C}$ for 24 hours. These overnight cultures were then diluted 1 in 1000 in PBS. The resulting bacterial suspensions contained approximately $10^{6} \mathrm{cfu} / \mathrm{ml}$.

The antimicrobial activity of each of the different elastomer samples was then assessed using the following assay. Triplicate samples of each type of elastomer $(\mathrm{TBO}+, \mathrm{MB}+$, untreated) were placed onto raised platforms (plastic lids) inside separate wells of two 6-well tissue culture plates (Sarstedt, Leicester, UK). Aliquots $(25 \mu \mathrm{L})$ of the microbial suspension were carefully placed on the surface of each elastomer sample and a glass cover slip was gently placed on top. The microbial suspensions were irradiated with light $(634 \mathrm{~nm})$ from a $1.0 \mathrm{~W}$ laser (BFi Optilas Ltd., UK) for up to 4 minutes, or incubated for the same length of time in the dark in the case of control samples containing TBO; samples containing MB were irradiated with light $(660 \mathrm{~nm})$ from a $230 \mathrm{~mW}$ laser (Periowave, Ondine Biopharma Inc.,Vancouver, Canada) for up to 21 minutes, or incubated for the same length of time in the dark in the case of controls. The irradiation power associated with the laser employed for TBO was $0.19 \mathrm{~W} /$ $\mathrm{cm}^{2}$, whilst it was $0.0325 \mathrm{~W} / \mathrm{cm}^{2}$ for the laser used with $\mathrm{MB}$.

$10 \mu$ aliquots of the bacterial suspension were then plated out onto either Mannitol Salt agar (MSA) in the case of S. epidermidis or MacConkey agar (MAC) in the case of E. coli. The remaining $15 \mu \mathrm{l}$ of suspension was removed from each polymer sample by pipetting and added to $135 \mu \mathrm{l}$ of sterile PBS in a $50 \mathrm{ml}$ tube (Sarstedt). The elastomer samples themselves were then carefully removed and added to the corresponding tubes. All samples were briefly vortexed and further serial dilutions were prepared in sterile PBS. Duplicate $25 \mu \mathrm{l}$ aliquots of each dilution were then plated out onto either MSA or MAC. All plates were incubated aerobically at $37{ }^{\circ} \mathrm{C}$ and survivors were then enumerated by viable counting after 24 hours in case of $E$. coli and 48 hours in case of $S$. epidermidis.

\subsection{Statistical analyses}

The Mann-Whitney $U$ test was used to compare the number of survivors recovered from the various silicone samples $(\mathrm{L}+\mathrm{S}+, \mathrm{L}$ $+\mathrm{S}-, \mathrm{L}-\mathrm{S}+$ ) with the number of survivors from the control samples $(\mathrm{L}-\mathrm{S}-)$. For all analyses, $p<0.05$ was considered statistically significant.

\section{Results and discussion}

\subsection{Synthesis and characterisation}

An activated silicone polymer was made by modification of a literature procedure reported by Chen et al. ${ }^{15}$ The authenticity of the intermediates in the synthesis was checked by proton and carbon NMR and shown to be identical to that previously reported. ${ }^{15}$ Further FTIR analysis of the activated surfaces of 1 (Fig. 1) was performed in transmittance and reflectance modes. Both showed a peak at $2166 \mathrm{~cm}^{-1}$ characteristic of a $\mathrm{Si}-\mathrm{H}$ bond, confirming that the silicon had been activated. The FT-IR analysis was repeated after the reaction of $\mathbf{2}$ with $\mathbf{3}$, and as expected the spectra did not show a $v \mathrm{Si}-\mathrm{H}$ stretch but did show the extra peaks associated with the functionalised polymer. This indicated that a reaction had occurred between the glycol derivative and the activated silicone surface. The Toluidine Blue $\mathrm{O}$ and Methylene Blue were attached to an activated silicone polymer by means of condensation reaction to form an amide linkage (Fig. 1).

\subsection{Characterisation of the TBO- and MB-bound silicone samples}

The UV-visible absorption spectra obtained for both MB- and TBO-treated surfaces are shown in Fig. 2. Relatively weak, yet characteristic, absorption spectra were seen at $\lambda_{\max } \approx 600 \mathrm{~nm}$ for the $\mathrm{MB}$ and $\lambda_{\max } \approx 560 \mathrm{~nm}$ for the TBO-treated samples. The position of the absorption maximum is red-shifted with that expected for the free dye in water by $c a .50-60 \mathrm{~nm} \cdot{ }^{13,14}$ The UVvisible absorption spectra are consistent with the dye being chemically bound to the silicone surface and the maximum is shifted because of the different matrix and slight difference in dye-structure due to the bond between the dye and the silicone surface. An extensive series of experiments using water and PBS showed that no MB or TBO could be detected by UV-visible spectroscopy as having been leached from the polymer, again consistent with a covalently bound dye.

The concentration of $\mathrm{MB}$ in the sample was determined using data from previous work done by the authors on MB that was physically incorporated into the silicone matrix. ${ }^{13}$ Following this procedure, the surface coverage of $\mathrm{MB}$ chemically bound to 

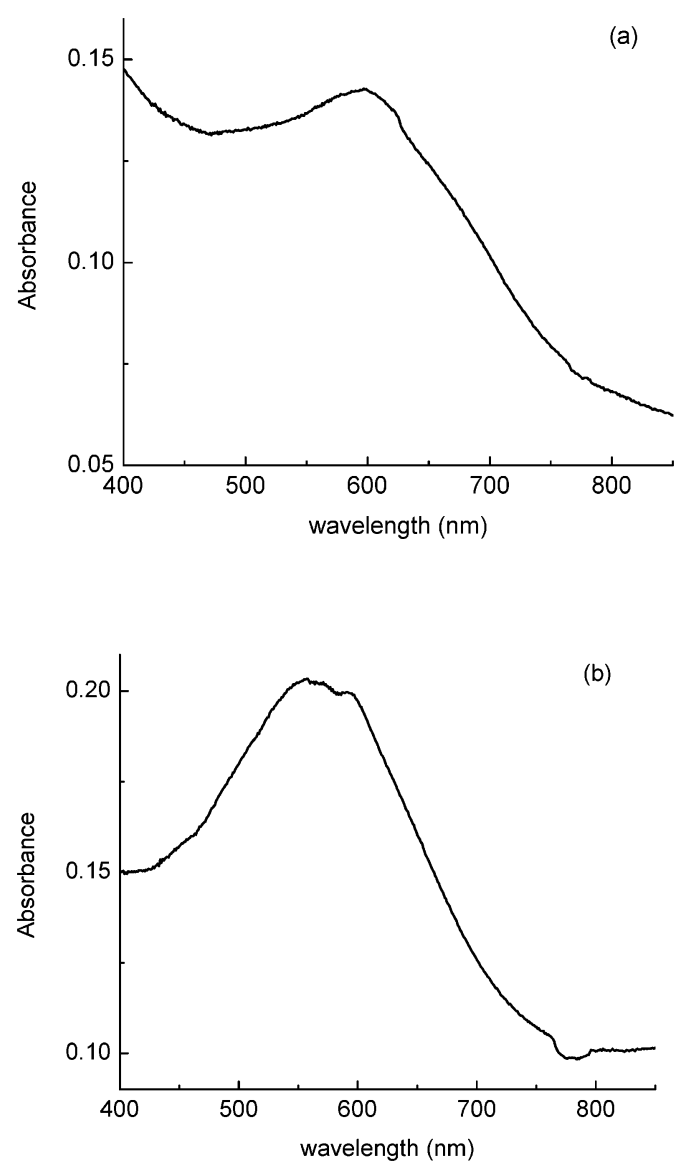

Fig. 2 UV spectrum of silicone sample with (a) MB and (b) TBO chemically bound to its surface.

silicone was estimated as $1 \times 10^{-6} \mathrm{mg} \mathrm{MB} / \mathrm{mm}^{2}$ of silicone. The same procedure was followed to estimate the TBO surface coverage; $2.5 \times 10^{-6} \mathrm{mg} \mathrm{TBO} / \mathrm{mm}^{2}$ silicone.

\subsection{Antibacterial activity}

The inactivation of $E$. coli on the surface of both MB and TBO treated polymer surface when irradiated with a low power laser can be seen in Fig. 3. It shows how the number of viable cells recovered from the sample containing $\mathrm{MB}$ or TBO after irradiation decreased with the energy dose delivered by the laser. The figures are plotted against irradiation energy rather than time, because two different lasers were used in these experiments. The two different laser frequencies allowed better matching with the absorption maximum of the dye. An energy dose of $42 \mathrm{~J}$ per $\mathrm{cm}^{2}$ was sufficient to generate a $1.3 \log _{10}$ reduction in the viable count of E. coli in the MB-bound surface (Fig. 3a) and a $2 \log _{10}$ reduction for the TBO-bound surface (Fig. 3b). Notably, zero kill was observed for the untreated polymer sample $(\mathrm{L}+, \mathrm{S}-)$, for the treated polymer sample in the dark $(\mathrm{L}-, \mathrm{S}+)$ and for the untreated polymer surface in the dark $(\mathrm{L}-, \mathrm{S}-)$. This indicates that both the dye-attached surface and the presence of light are required for bacterial kill. The bacterial kill for the TBO-treated surface was greater than for the MB-treated material and correlates with the higher calculated amount of dye per unit area in the case of TBO.
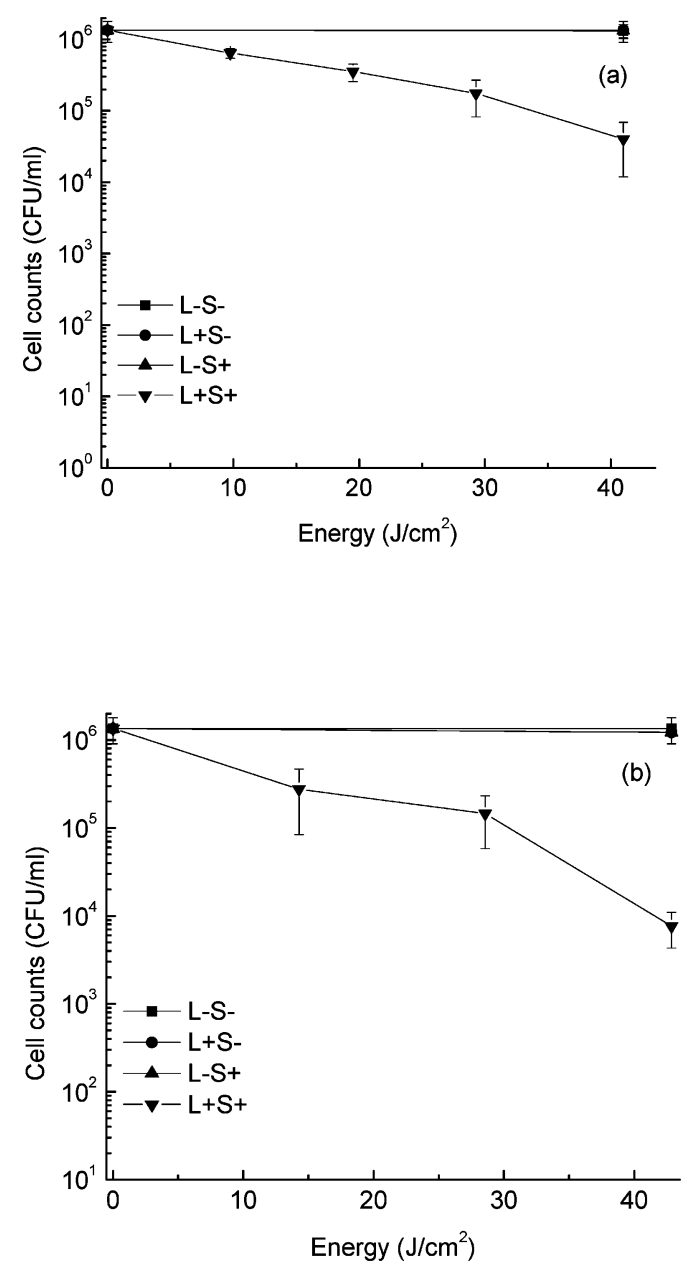

Fig. 3 Inactivation of E. coli on (a) MB-bound silicone rubber; (b) TBObound silicone rubber.

Fig. 4 shows the inactivation of $S$. epidermidis on the same materials; the reductions in viable count using both MB and $\mathrm{TBO}$ bound to the surface are significantly greater than in the case of $E$. coli, with the number of viable cells recovered falling below the detection limit after $20 \mathrm{~J} \mathrm{~cm}^{-2}$ in the case of MB (Fig. 4a) and after $28 \mathrm{~J} \mathrm{~cm}^{-2}$ in the case of TBO (Fig. 4b). Furthermore, the control samples $\mathrm{L}+, \mathrm{S}-, \mathrm{L}-, \mathrm{S}-, \mathrm{L}-, \mathrm{S}+$ all showed zero kill. The fact that MB is faster at killing $S$. epidermidis at a lower surface concentration than TBO indicates that it is more potent at killing this bacterium under the conditions tested.

The data for both $S$. epidermidis and E. coli show how both systems have very potent antibacterial properties, despite the very low concentration of the LAAAs. We have previously reported the bacterial kill for polymer surfaces prepared by the swell-encapsulation process, the amount of dye present in the silicone was substantially higher. ${ }^{13,14,17}$ For example the maximum UV-absorption for the physically-bound MB reached $0.8 a u$ compared to $0.15 a u$ obtained in the case of MB absorbed by the polymer; however the antimicrobial properties at these relative amounts were found to be comparable. This can most readily be explained by the fact that the antimicrobial property of 

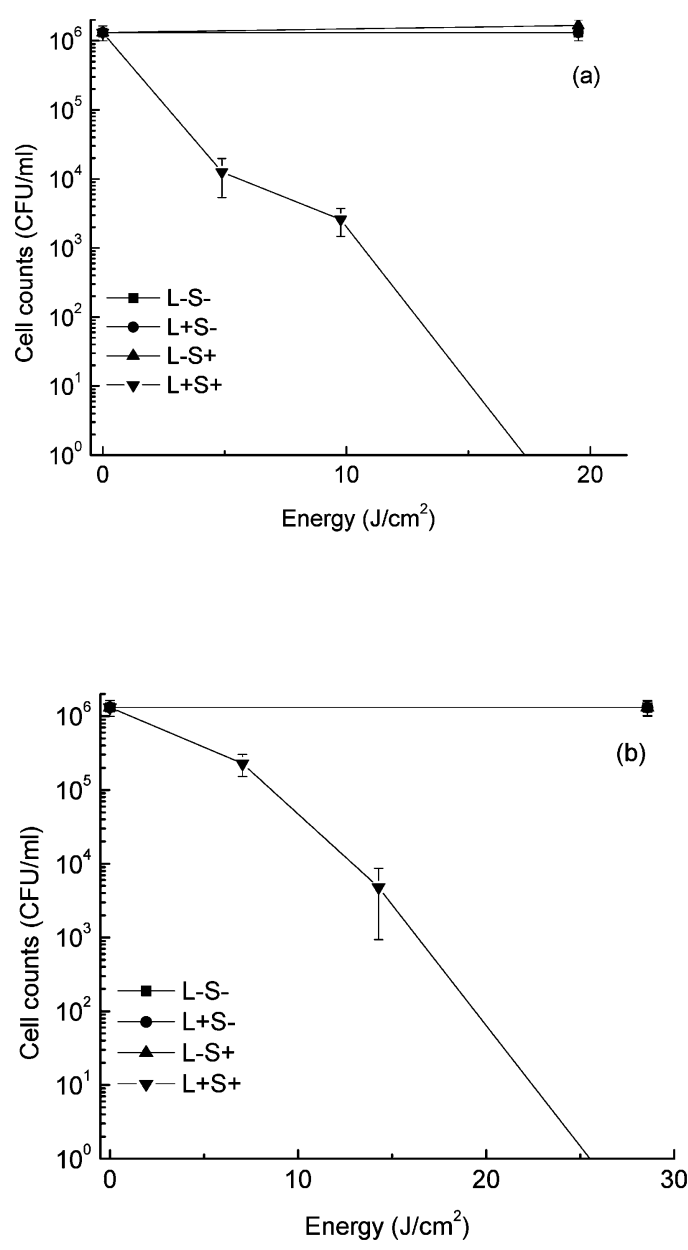

Fig. 4 Inactivation of S. epidermidis on (a) MB-bound silicone rubber; (b) TBO-bound silicone rubber.

the dyes is due to the production of reactive oxygen species typically singlet oxygen or the hydroxyl radical. These species have relatively short diffusion distances within a polymer, and are most potent when generated at a surface. Because the covalently-bound polymer has the dye at the surface it shows exceptional kill because the generated radicals are in the best position to attack surface-located bacteria.

In previous work we have shown that the kills achieved by a LAAA are related to the type of bacterium ${ }^{13,14,17}$ with Gramnegative bacteria such as $E$. coli being less susceptible to killing than Gram-positive bacteria such as S. epidermidis. This is a result of the different bacterial cell walls which have different sensitivities to radical attack. The results presented in this work are consistent with these findings, and are due to differences in the cell wall structure between Gram-positive and Gram-negative organisms.

The polymers with covalently-bound dyes have a number of advantages over polymers with physically-absorbed dyes. Firstly, the colour of the polymer that is required for significant bacterial kill is barely noticeable for the covalently-bound dyes, whereas for the physically-absorbed dyes the material is highly coloured.
This is important for use as a catheter but more so for an antimicrobial surface for other uses, for example, computer keyboards or telephones in hospitals, where aesthetics may be more important. Secondly, the dye does not, within the limits of our experimentation, leach from the covalently bound dyes and finally, the polymer with covalently linked-dye is potent at killing bacteria even when the dye is present at a low concentration.

\section{Conclusion}

Silicone samples with either Methylene Blue or Toluidine Blue O covalently bound to its surface were successfully prepared. The UV-visible absorption spectra confirmed the presence of a very small amount of dye on the silicone surface. These materials display significant bactericidal activity against $E$. coli and $S$. epidermidis, despite the very low levels of either MB or TBO bound to the polymer. These findings suggest that these materials could be potentially used to reduce the numbers of viable bacteria on the surfaces of catheters and other surfaces.

\section{Acknowledgements}

The authors thank the BBSRC for the financial support (grant BB/E012310/1). IPP thanks the Royal Society/Wolfson trust for a merit award.

\section{References}

1 M. Wilson, Microbial Inhabitants of Humans, Cambridge, Cambridge University Press, 2005.

2 B. Trautner and R. Darouiche, Arch. Int. Med., 2004, 4, 842-850.

3 D. Maki, L. Mermel, Infections due to infusion therapy, in Hospital Infections, Philapelphia, ed. J. Bennett and P. Brachman, Lippincott-Raven, 1998, p. 689.

4 D. Veenstra, S. Saint and S. Sullivan, J. Am. Med. Assoc., 1999, 282, 554-560.

5 N. P. O’Grady, M. Alexander, P. Dellinger, J. L. Gerberding, S. O. Heard, D. G. Maki, H. Masur, R. D. McCormick, L. A. Mermel, M. L. Pearson, I. I. Raad, A. Randolph and R. A. Weinstein, Pediatrics, 2002, 110, 51-75.

6 S. Slaughter, Postgrad. Med., 2004, 22, 59-66; A. MacRoberts, S. Bown and D. Phillips, Ciba Found. Symp., 1989, 146, 4-12.

7 N. L. Oleinick and H. H. Evans, Radiat. Res., 1998, 150(5), S146S156.

8 R. A. His, D. I. Rosenthal and E. Glatstein, Drugs, 1999, 57, 725-734.

9 N. Kömerik and M. Wilson, J. Appl. Microbiol., 2002, 92, 618-623.

$10 \mathrm{~J}$. E. Wilson, C. Bull, Light-activated antimicrobial and antiviral materials. US Patent No. 6239048, 2001.

11 V. Decraene, J. Pratten and M. Wilson, Appl. Environ. Microbiol., 2006, 72, 4436-4439.

12 J. Gil- Tomás, S. Tubby, I. P. Parkin, N. Narband, L. Dekker, S. P. Nair, M. Wilson and C. Street, J. Mater. Chem., 2007, 17, 3739-3746.

13 S. Perni, C. Piccirillo, J. R. Pratten, P. Prokopovich, W. Chrzanowski, I. P. Parkin and M. Wilson, Biomaterials, 2009, 30(1), 89-93.

14 S. Perni, P. Prokopovich, C. Piccirillo, J. R. Pratten, I. P. Parkin and M. Wilson, J. Mater. Chem., 2009, 19, 2715-2723.

15 H. Chen, M. A. Brook, H. D. Sheardown, Y. Chen and B. Klenker, Bioconjug. Chem., 2006, 17, 21-28.

16 B. Xia, S. Xiao, D. Guo, J. Wang, J. Chao, H. Liu, J. Pei, Y. Chen, Y. Tang and J. Liu, J. Mater. Chem., 2005, 16, 570-578.

17 S. Perni, C. Piccirillo, P. Prokopovich, J. R. Pratten, I. P. Parkin, and M. Wilson, submitted to J. Mat. Sci.: Mater. Med. 